\title{
AN INTEGRATED MODEL FOR THE TREATMENT OF TIME IN MT'. SYSTEMS
}

\begin{tabular}{|c|c|}
\hline M. Meya & J. Vidal \\
\hline $\begin{array}{c}\text { Siemens CDS } \\
\text { c/Luis Muntadas, } 5 \\
\text { CORNELLA, 08940-BARCELONA }\end{array}$ & $\begin{array}{ll}\text { EUROTRA-L } \\
\text { Ctra. } \\
\text { Vallvidriera, } 25-27 \\
\text { O8O17-BARCELONA }\end{array}$ \\
\hline
\end{tabular}

Spain

Abstract

One of the ways to achieve a good translation of verbal forms is the morphosyntactic approach, which consists in a function pairing the different morphological tenses that occur in a given language with the tenses of the other language. Complicated rules must be established to calculate the right: paix for an expression, because of the amount of discrepancies that different languages show with respect to each other.

The way we have chosen to deal. with this problem is, conversely, the projection of the different values coming from verbs (type, processivity, morftense, morfaspect, moodrequirement), from adverbs, prepositional phrases and temporal Wes (deixis, aspect, iteration), and from subordinate conjunctions (aspect, moodrequirement).

All this information permits to obtain a final value for aspect and tense for the whole sentence, which later on is percolated, not only to the verb node, but also to the the rest of elements conveying information.

Oux proposal relies on the fact that tense/aspect calculation is relevant not only for a good translation of verbs, but also for a good translation of adverbs, PPs, temporal. Ni:s and conjunctions, as we have intended to demonstrate in this paper.

\section{Introduction}

This arcicle deals with a methodology to achieve the right transiation of temporal expressions by giving account of the temperal reference and temporal relations in/ between sentences. The task to accomplish is to translate syntactic unrks into semantic values that decide/ reflect the aspecturil value of the sentences.

Fol: our treatment of time and aspect we draw on the work of Kamy [1979] and Partee [1984] who have argued for taking status and events as primitives and relations of precedence und overlapping between them. The ordering relation betwen events is crucial for deciding about the aspect of thle sentences involved.

Tho present proposal presumes an analysis and a generation courponent that deliver a set of $\mathrm{s}$-trees whose leaves consespond to words. The pre-terminals have moxphosyntactic and relational information. As usual, festures ures percolated and nodes got features assigned. The tivo/ aspectual problem is dealt with under the perspective of mith the aim of sketching a ayatem that can be inplemented independently of the particular formalisms of differient MT-Bystems.
To outline general model for the time/aspect calculation in UT ve subsume a system with PSG rules that obtain some sentence structure with no regard to a specific grammax type; it could be an augmented PSG, as in METAL, or some kind of deep syntactic structure, as it is the case in Eurotra.

The problem is the well known fact that translations of temporal expressions in NL does not involve a simple mapping of tenses and adverbials. We could just compare Spanish, rich in aspect and tenses vs. German or English. That is, a dealing with Germanic and Romance languages is concerned with different parameters for each language; the whole practice in MT systems is to translate morphological tenses, and syntactical values into reforence times that include events or states [Partee 1984].

Once the set of factors and values relevant for the specification of time, aspect, and mood has been defined, a calculation or unification in the form of rules fixes the values that must be generated in the target language. Such a system must "preserve" the same "semantic interpretation" for different language realisations, in order to be able to generate the right morphological tenses and periphrasis froin language to language.

\section{Aktionsart}

Vendler's definition of Aktionsart [1967] relies on a classification of verbs into sentences. However, we start from verb primitives that are categorized (Verb Type) into:

- stative : to be in love, stand, know..

- dynamic : vite, arrive, love,..

and we take an additional feature "Processive" to mark the differences between activities vs. accomplishment, achievement ox quality/state vs. stance (R. Quirk 1985).

The inherent type of these verb primitives is overridden during. the analysis by the morphological tense and by the syntactic functions, so that we finally obtain a 
value for the Aktionsart of the whole phrase.

- write (escribir): VI = activity, proc Fyes (a durative verb)

- cend (enviar) : VI = activity, proc $=$ no

(a punctual verb)

The original aktionsart of the verb, durative activit, $y$ becomes an accomplishment in the sentence "I mote a lettex". In Spanish this information must be marked in order to choose the right past form.

[escribió [una carta]] $\rightarrow \rightarrow$ Vractivity proc=no

[escribía] $\rightarrow$ AKT=activity $\Rightarrow$ tense=Imperfect

3. Deixis

The calculation of the time value, which is always expressed as a deictic value relating the speech time to the reference time, is obtained out of the dejatic values of the morphological tenses together with the adverbials present in the sentence. For instance, the spanish present tense has the value [sinultaneous and posterior]. If it appears with a posterior adverbial, the final value is posterior. The deixis assigment in Spanish is reflected in table 1. The left side is the assigment in context with no temporal transposition; the right side shows the assigment for tense transposition. The context for tense transposition is given for knowledge and diction verbs.

Table 1 : Deictic assigment to the tenses in Spanish

\begin{tabular}{|c|c|c|}
\hline No Tense Tran & position & Tense Transposition \\
\hline Tense & Deixis & Deixis \\
\hline $\begin{array}{l}\text { Present } \\
\text { Past1 (Indefinido) } \\
\text { Past2 (Imperfecto) } \\
\text { Future } \\
\text { Conditional }\end{array}$ & $\begin{array}{l}\text { simul, post } \\
\text { ant } \\
\text { ant } \\
\text { post } \\
-\end{array}$ & $\begin{array}{l}\text { simul, post } \\
\text { ant } \\
\text { simul } \\
\text { post } \\
\text { post }\end{array}$ \\
\hline
\end{tabular}

Temporal modifiers can belong to different classes:

1 - Adverbs: in this case the deictic value comes from the dictionary

2- PP: the deictic value comes from the Preposition

3 - NP: The deictic value is the result of two factors:

a) the demostratives and

b) the temporal type of the singular noun

WP' when temporal designators have the Deixis [ant, post]. When thoy appear with a pluxal definite axticle, this is an operator that overrides the original deixis values and yields the iterative aspect. i.e.: "el lunes "[past, ante] [="on monday") vs. "Ios lunes" [itex] (on mondays)

The deixis feature is the discriainating factor to get the right transfer for "lunes".

4 - Subordinate clauses : the deictic value of this adverbials is a calculus of the deictic value of the conjunction (if present), and that of the tense and of the mood, if present.

There are two possible cases depending on the source language ( Germanic or Romance). For the first case, the aspectual value of the conjunction and the temporal value of the wain clause select the mood of the subordinate clause. The deixis value of the main clause is copied onto the subordinate conjunction; this value decides wout the subjuntive reguirement of the conjunction. Let's take the conjunction "till" (Eng.), "bis" (Gera.), "hasta que" (Span.) that has no deictic value. If the main clause is in future, "till" gets the deixis "post", if it is past then it gats accordingly the deixis "ante".

The intaresting fact is that, according to the obtained deictic value the conjunctior, selects the aubjunctive requirement. When the conjunction has assigned in the lexicon the comatiment of eubjunctive requirement, this value is the most relevant. For example:

"I will[pogt] work, till[post] you come" "Irabajard[post], hasta_que[deixis=post] vengas" $\Rightarrow$ [subreqzyas]

"Ex arboitete[ante] bis [ante] or kam" "Trabajó [ante] hasta que[doixis=ante] Ilagólante]"

Therefore the following general, rule can be

formulated:

Source Conjunction [post] $\Rightarrow$

Taxgat-Conjunction [aubrequases]

Again the deixis value also enlects the right. transfer of the conjunction. Hex some examples for Spanish and German: 


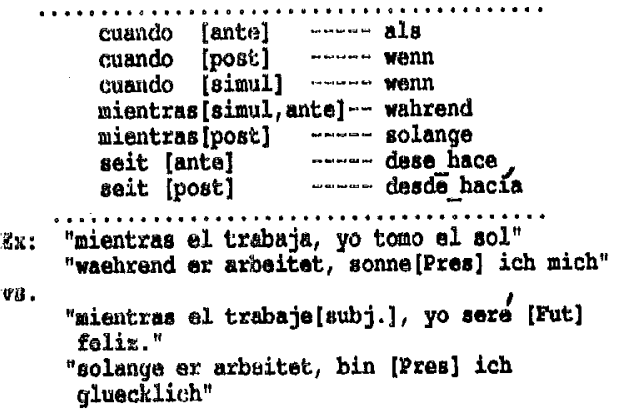

4. Aspect

The abpectual calculus we propose relies on:

- I) Lexical type of the verb prinitives

- 1) moxphological tenses of the verb forms

. i) the presence of temporal adverbials.

if) the degree of definiteness of the sentence constituents.

The possible aspecturl. values are: [inchoactive, durativo, terminative, perfactive, retrospective, prospectivi].

Wh: Lexical tipology was already mentioned: the Verb dype (VI) theature, and the Proctessive Feature.

4.1. Calculus of the Aspect of the verb group

In order to cover a.ll the aspectual meanings in Spanish to keep progressivity as value out of the aspectual Seature bessuse it does not appear in alternance with the other valuss. The way to proced in the calculation of the aspectual. yalue is the following:

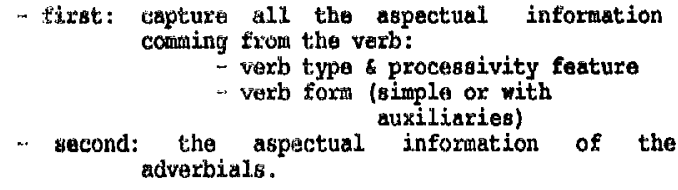

Tho aspectual assigment to the tenses in Spanish is shom in tablo 2.

Table 2: Aspect vulues for verbs in Spanish

\begin{tabular}{|c|c|c|c|c|}
\hline 3ouxce Information & & \multicolumn{3}{|c|}{ nesulting Information } \\
\hline Varb toxa & process & VRB-IYYPe & Aspect & $\log$ \\
\hline 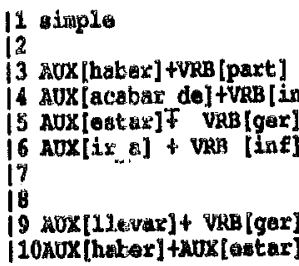 & 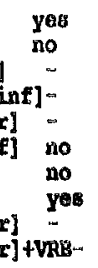 & $\begin{array}{l}- \\
- \\
- \\
- \\
\text { atat } \\
\text { dyn } \\
= \\
=\end{array}$ & $\begin{array}{l}\text { durative } \\
\text { |perf., iter } \\
\text { |rotrospect. } \\
\text { |retro.6inman. } \\
\text { |durative } \\
\text { |inchoactive } \\
\text { iprospective } \\
\text { inchoactive } \\
\text { |inerwinative } \\
\text { | retrospective }\end{array}$ & $\begin{array}{l}\text { no } \\
\text { no } \\
\text { no } \\
\text { no } \\
\text { yes } \\
\text { no } \\
\text { no } \\
\text { no } \\
\text { yos } \\
\text { yes }\end{array}$ \\
\hline
\end{tabular}

3x:

"Goubo de llegax" wi have juat [prox.] arrived "let trabajando" joh bin gerado [prox.] gokomen Ho is workingldur, a prog.] Fir arbaitet gerade [prox.]
The relevance of the presence/absence of the progressivity can be shown when we translate into Grouk. In this language the same aspect value generates different tenses according to presence or absence of progressivity. For instance, if aspect is retrospective and thise is prograssivity then the corresponding tense is Imparfect, but if there is no presence of progressivity the corresponding tense for this aspect is Present perfect.

The moxphological tenses also imply monolingual aspectual assignments. Here we will follow the proposal of F. van Eynde. According to it, each language has a different distribution of aspectusl features in tenses. However, here again we prefer to split up the moxphological values according to two attributes : form and progresivily form.

4.2 Aspectual value of adverbials

Adverbs as well as prepositions and conjunctions have in the lexicon an aspectual value assignent. Temporal NP's as adverbials get the aspectual assigment from their determinants or quantifiers. Bare plurals or distributive cquantifiers assign the value [iterativity], while All-cuantifiers furnish the NP with durativity, expressed in some languages as progressivity.

"Lr arbeitet den ganzen Tag" -..- Esta trabajando todo el dia

For instance, iterativity must be delivered from the source language in order to generate the right tense even for punctual verbs. e.g.:

"un día envió flores a Carmen" =

"he once sent flowers to Carmen" vs.

"enviaba cada día flores a Carmen"=

"he sent to Carmen flowers every day"

Determiners/quantifiers have aspectual values as:

un [perf]; cada [ iter]; todas [iter]; todo/a [dur]

so the transfer of "día" is "once" if we are concerned with perfective UP-adverbial. However the transfer of "dfa" es 'day' when the aspectual calculus has furnished the NP with the feature [dur] or [iter].

In $\mathrm{PP}^{\prime} \mathrm{s}$ the final aspectual value is the rusult of the calculus of the aspect value of the preposition together with the deixis of the adverbial. For instance, the boundary preposition "deade" (aince) with anterior adverbials yields a final teminative apect, but with a posterior adverbial, or even with a anterior adverbial but together with another boundary expression (the final point of the temporal) it yields a porfective aspect. Examples:

"desde ayer[ante] trabaja aqui" $\quad-\rightarrow \rightarrow$ terminative
"desde ahora trabajard en EUROrRa" $\quad-\rightarrow-\rightarrow$ parfective 
"trabajo aquil desde el lunes hasta el jueves" -->perfective [perf] [limitliterm] [1imit 2=perf]

The resulting aspect value of this calculus must be attached to the preposition or adverb (overriding) the old values in order to get the right transfer.

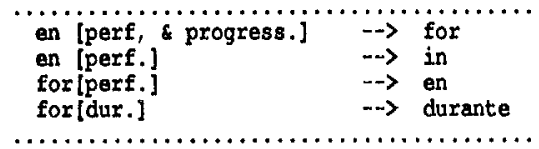

In subordinate clauses the process is the same. As we have seen above the deixis of the calculus of the main clause must be attached to the conjunction. Thus, the calculus of the aspect of the main clause must be furnished to the conjunction in order to be able to get the right transfer of the conjunction and also for generating the right tense in the subordinate clause.

Another important factor in the calculus of the aspect is the syntactic type of the constituents in the sentences. These determine the aspectual properties (Dowty). To illustrate it we take the examples of Dowty (1986)

$$
\begin{aligned}
& \text { "John walked" } \\
& \text { "John walked to the station" -- fue a la estación } \\
& \text { [activity] } \\
& \text { "John walked a mile" }
\end{aligned}
$$

As we can appreciate, the Spanish sentences have a different lexical verb form for each of these aspectual differences. Up to now METAL have different transfers according to the different verb frames. Eurotra-Gerwany proposes to disambiguate in the Interface Structure by means of semantic feature bundles. Besides the constituency factors of the syntax, another important fact is the presence/absence of bare plurals for the objects:

$$
\begin{aligned}
& \text { "Heva escribiendo novelas tres años" -- } \\
& \text { "she has been writing novels for } 3 \text { Yeara" } \\
& \text { "sie schreibt Romane seit } 3 \text { Jahren" va. } \\
& \text { "He wrote a novel" -- "escribió una novela" } \\
& \text { [Past, perfective] } \\
& \text { "He wrote novels" --- "escribia novelas" } \\
& \text { [Past, durative] }
\end{aligned}
$$$$
\text { That means that the original verb value for }
$$

processivity is overriden according to the NR's that go with the verb. NP's with quantifiers assign the aspectual values so that punctual verbs express processes, or viceversa.
5. Process for the calculus

The calculus of time and aspect can be implemented either as:

- a unification of features together with filters that: catch or kill complex cases. (BUROTRA)

- an assigment table gathering the possible IME and ASPECT configurations, and another table yielding the TENSE corresponding to each of the TIME/ASPECT configurations for the right target language generation.

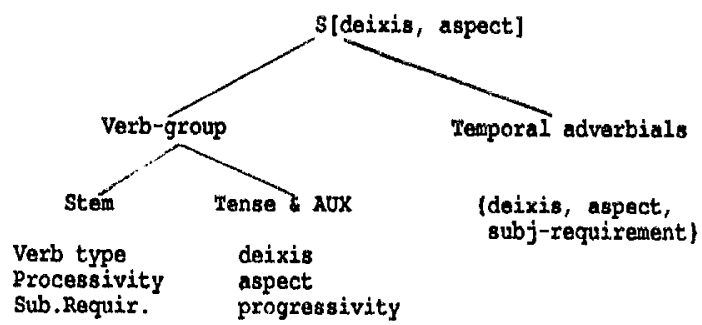

The calculation process delivers a final value as a result which must be percolated to the $S$ node. This process has the characteristic of a functional composition, provided that the different values can be considered as operators applied in a hierarchical order. The dominant value is the adverbial.

[Adv. (post) [V (simuI, post)]] $\rightarrow$ S (post) [Adv . (term) [V (perf, dur)]] -.>S (tern)

$$
\text { The calculus provides a value for } S \text {, and }
$$
s-subclauses, but also for all the temporals implied so that they can be properly translated into morphological values, or into lexicalized forms.

7. Summary

In NL processing the calculus of Time and Aspect is a complex thing where almost ald elenents of the sentence are concerned. The dynamics of the aspect and deixis in Natural Language can be captured in the framerork of a calculus of these. Some tables in this article give acquitance of this process. The originality of our proposal relies on the following aspects:

- Onicity of criteria (the same features for all temporal categories)

- Unicity of adverbial types (the same treatment for subordinated temporal clauses, for adverbs and PP's.

- A strong interrelation of the aspectual modal and deictic values in the constituents of the sentence. 
Datachent of the varb privacy for aopact in favor of a bi ofirectional intrerelation. That weans, the vetb tan be correctly translated if the vobjact/object daterainacy is taken into account.

roscefore, the right tonse and the right tranafer fiot the adverbials can be only generated in harmony with the global calculated aspect and deixis.

8. Hoforations

i. Argalo : A cokapositional approach to the translation of coitgowal. sxpressions in the Rosseta Systean. In Procesdings of the Coling 1986 . Bonn. p. 313-318

4. Hach (1986) The algabre of events. Linguistics and Qhidogehy, $8,5-16$

V.4. Bued R.A Smiti : Temporal Relations. To appear in Jousial fox" berantice (Nijmegen)

V. Lo Cancio co vot $\mathrm{Ch}$. Rohrer : Inyteraction between Vorbal denses and Tefuporal Adverbs in Complex sentences:

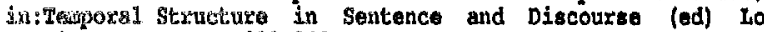
Cascio \& Co vet p. $229-249$.

13. Bakiea (1984) kominal and Temporal anaphora", Iinguistics and thilosophy, $7 \quad(243-286)$

19. Dotry the effacts of aspactual class on the temporal besueture of Discourse: Semantics or pragaties, Linguistics and philosogky, $9(37-61)$

w. vall Eynde 'ding a unified theory of tense, aspect and Kktionsaxt. Unpublished. 1987

S.Lobnar :knsagtze oiner integralen semantischen Theorie vor Terdipos, Aspect und Aktionsarten. To appear in: (ed) V. Which und E. Vatex: Temporalsemantik. Niemayer. Tuebingen. 